\title{
La referencialidad americana
}

The American referentiality

José Pablo Concha Lagos

Instituto de Estética, Pontificia Universidad Católica de Chile.

jconchal@uc.cl

\section{Resumen}

Este artículo trata de pensar las relaciones críticas entre América y Europa como lugares de mutua referencialización desde el orden fotográfico. Las dimensiones fundamentales que se ponen en juego acá son el tiempo y el espacio, mediados por el dispositivo técnico fotográfico, el que será observado desde la perspectiva de un aparato que encarna una ideología que se impone críticamente al espacio americano, evidenciando diferencias fundamentales.

Palabras clave: Fotografía, referente, espacio, tiempo.

\section{Abstract}

This article tries to think about the critical relations between America and Europe as places of mutual referentialization from the photographic order. The fundamental dimensions that are put into play here are time and space, mediated by the technical photographic device, which will be observed from the perspective of an apparatus that embodies an ideology that is critically imposed on the American space, evidencing fundamental differences.

Keywords: Photography, reference, space, time. 
¿Cuál es el mapa mental por trazar? Así nos interpela Ronald Kay mostrándonos una falta, algo que aún no se realiza. En la segunda parte de Del espacio de acá... titulada “Teoría” nos expone los alcances que estima tendrá la lectura de lo que sigue: una serie de ensayos teóricos que abordan diversos tópicos, todos relativos a la relación compleja entre Latinoamérica, fotografía, representación, tiempo y espacio, terminando este breve párrafo con la indicación que todo lo siguiente es el mapa mental que debe ser diseñado. Es una tarea por hacerse, por lo tanto, es un trabajo seminal el de Kay. ¿Qué es lo no dicho hasta ahora? La relación referencial entre estos asuntos.

Entendemos que la tesis más compleja y que mayor repercusión ha tenido es la relativa al establecimiento de una visualidad americana antes por la fotografía que por la pintura, tesis que vendría a desbaratar la tradición pictórica americana y chilena más específicamente. En este caso, no abordaremos esta especificidad temática, sino más bien nos centraremos en el rendimiento teórico que algunos conceptos permiten en la relación referencial entre América y Europa, mediados por un dispositivo técnico, en este caso la fotografía. Esta mediación técnica, más allá de las consecuencias culturales, tratará de ser pensada acá en el ámbito más bien conceptual, en el contexto de reflexiones relativas al tiempo, espacio y referencialidad.

Partamos por la dimensión tal vez más complicada, el tiempo. Kay lo piensa situándolo en circunstancias diversas, a partir de su determinación técnica, en tanto mecanismo que funciona a partir de operaciones que se expanden y contraen en medidas estandarizadas; o, desde evidencias fenomenológicas extravagantes, como la manifestación material de un mismo cuerpo o acontecimiento en dos lugares simultáneamente. Entendemos que la temporalidad presentada implica una comprensión epocal, por lo tanto coherente, de la que produjo el aparato fotográfico mismo en el siglo XIX, pero este aparato tendría la capacidad de desmantelarlo y desmantelarse desde su propio interior. El tiempo como un continuo es equivalente al reloj como sometido al orden causal que se origina en el mismo big bang. Lo interesante es que este tiempo se debe a la extensión espacial y su posibilidad accidental de recorrerlo. El tiempo se evidencia en la materia, se precipita en espacio, como lo dice a pie de página en el "Tiempo que se divide", esta sería una condición única de "lo fotográfico", es una transformación de carácter ontológica, casi como una metamorfosis al modo alquímico: una naturaleza muta esencialmente en otra. En este caso es una dimensión de orden trascendental, en la estética kantiana, que se convierte en otra. Este acontecimiento está comprendido en lo que el propio Kay llamó la "catástrofe cósmica", la que nosotros interpretamos como una alteración fundamental de los principios del acontecer de los fenómenos, entendiendo a este acontecer, precisamente desde la convención física newtoniana. Pensemos, como posibilidad proyectiva, en la pregunta que se hace Bachelard ¿el tiempo es duración o instante? Este problema es atingente porque expone las respuestas posibles a una fenomenología de la temporalidad, que se determina ya no desde una epoché, sino más bien desde la particularidad contingente. Si seguimos la metodología de Kay cuando escudriña el interior del dispositivo 
técnico para llegar a asuntos más bien filosóficos, debemos entrar a la operatividad técnica de la cámara y pensar en la fracción de segundo que se juega la totalidad de la representación. ¿Esa fracción es instante o duración? La cámara fotográfica no discrimina la diferencia entre las diversas temporalidades, sino que constriñe lo visto a sus propios términos ¿cuáles son los diversos tiempos posibles en el acto fotográfico? El del operador de la cámara, el tiempo de la cámara y de aquello que está delante de la cámara. La única variable constante es precisamente el aparato fotográfico; es decir, este impone nuevamente sus términos a aquellos con que se vincula. Justamente desde aquí se puede pensar la distinción entre el tiempo técnico y el existencial. El primero es instante y el segundo es el de la duración. El primero es medible, el segundo no tiene referencias materiales. La cámara opera desde el tiempo técnico y se impone al existencial, y de algún modo este figura la colonización temporal, pero la condición de objeto del dispositivo técnico está, a su vez, determinado por la temporalidad de quien le dio origen, es decir, la temporalidad como medida diacrónica constante, propia del siglo xıx. La relación entre las temporalidades revela la preeminencia de una sobre la otra, dependiendo de la valoración asignada a cada una de ellas; esto tendrá como consecuencia significativa la ubicación, en el horizonte interpretativo, del tiempo de aquello que está frente a la mirada. Es decir, el tiempo asigna el sentido. Por lo tanto, necesariamente habrá colisión de tiempos. La temporalidad absoluta al interior de la imagen fotográfica de un acontecer que se despliega diacrónicamente, definirá esta colisión. Kay dirá que "La fotografía retarda el tiempo hasta el punto de su detenimiento" (20) y, como ya decíamos, que "el tiempo se precipita en espacio" (21), es decir, que estas dos dimensiones se co-pertenecen y se determinan. Pero, siguiendo la lógica del propio Kay, primero sería el tiempo que luego deriva en espacio. Esta linealidad es fundamental para entrar en el problema de la referencialidad fotográfica, así como de la relación centro-periferia que propone Del espacio de acá... Es decir, el referente del espacio sería el tiempo y el referente del tiempo, el sujeto que lo piensa; digamos en este caso el sujeto colectivo, o más radical, la cultura que envuelve al sujeto colectivo. Desde acá, la temporalidad (como matriz cultural) que produce al dispositivo técnico fotográfico impone su diacronía estandarizadora a lo fotografiado como acción conquistadora respecto de aquello que es fotografiado y que no pertenece a su tiempo y espacio. Este movimiento, que Kay lo vio en lo acontecido con la fotografía de los sujetos fueguinos, llegó a su máxima expresión en la fotografización de la contemporaneidad. Occidente se apropió de la imagen del mundo, o más complejo, Occidente estandarizó la imagen del mundo a la imagen de Occidente. De este modo, la referencialidad desde la imagen fotográfica ya no es el objeto instalado en la "realidad" delante de la cámara que aparece en la foto, sino que ese objeto aun cuando, eventualmente, distinto del tiempo y del espacio fotográfico, es referencia del propio Occidente, no hay realidad referencial posible del objeto en la fotografía. El referente queda sometido y al servicio utilitario de la matriz de sentido que produjo la fotografía. 
La lógica referencial encuentra un fundamento en la idea de "útil”: todo sirve para algo y es ahí donde se encuentra su sentido, ya no en el objeto mismo. Esta proposición inhabilita cualquier posibilidad de reconocimiento ontológico y, más bien, podríamos hablar de identidad desplazada hacia la utilidad. Ni siquiera los "conceptos", como figuras abstractas y pretendidamente autoreferenciales, se salvan de la utilidad. ¿Cómo pensar la referencialidad centro-periferia? Como autoafirmación y como deseo. ¿Cuál sería el objeto y cuál sería el referente? América como objeto supondría al centro como referente. Esta disposición de elementos resulta reconocible si consideramos a América como un espacio derivado, como resultado de la colonización, asumiendo que la matriz desde donde toma forma Occidente es el centro hegemónico. Por ejemplo, si el lenguaje unifica al extenso territorio latinoamericano, absorbiendo los particulares, las modulaciones locales resultarán como derivaciones de ese origen lingüístico, en este caso el español. Pero si pensamos al lenguaje como un útil, las razones que lo configuraron en el origen nada tienen que ver con la referencialidad americana; se produce un descalce fundamental. El uso de un determinado lenguaje no significa la incorporación de la cultura que le dio origen. Más claro aparece este problema desde el ángulo contrario ¿asegura la comprensión de las modulaciones latinoamericanas el solo hecho de compartir el lenguaje con el centro? Naturalmente no...

Esto nos obliga a pensar si es Latinoamérica referente europeo y si lo fuera qué podríamos decir de esta relación... Como lo plantea Rojas Mix, nuestro territorio es la posibilidad de autoafirmación civilizatoria europea como margen exótico (1991). La proyección del imaginario mítico hacia nuestro territorio lo confirmaría. El referente en este caso opera como objeto de una imagen que establece la distinción entre civilización y barbarie que, como dice Vilfredo Pareto citado por Rojas Mix: "la barbarie no hace sino continuar la idea de Aristóteles de la servidumbre natural..." (20). Esto quiere decir que la cultura dominante necesita de otro para afirmarse en sí misma y para ello es eficiente encontrar a otro sometible, sea física o simbólicamente, es decir, se identifica la legitimidad de la subordinación en la necesidad de afirmación identitaria. Así como los persas son a los griegos en la antigüedad, Latinoamérica es para Europa; siendo España la que establece una relación más compleja con nuestra región, desde la perspectiva de definición de una visualidad latinoamericana a partir de sus propias expectativas.

De esta manera, y como lo planteamos más arriba, lo que nos dice Kay es especialmente importante al momento de insistir que la cámara fotográfica impone sus términos, estandariza todo aquello que entra en su programa (acá es interesante agregar que nuestro autor se adelanta a Flusser en este asunto), pero además lo desacraliza y desmitifica; pero, en este caso, el hecho obliga a confirmar a este nuevo territorio, a pesar de la fotografía, como el lugar de la diferencia. Es así como el aparato fotográfico, junto al prestigio de su aparición, vendría a confirmar esta diferencia. Este descalce, nos propone Kay, es la justificación clave para pensarnos desde el espacio de acá. 
En "La reproducción del nuevo mundo" nos dice “... el medio de registro que es el lente, marca y traduce, como heterogéneo a él, aquello que hace ingresar a su documental de la escena americana [...] bajo la especie de lo exótico" (27). Más adelante agrega: "El efecto específico de la intervención fotográfica en América: la producción de una unidad significativa, que contiene en cuanto imagen una discontinuidad temporal que la constituye y en la que se citan dos tiempos históricos distantes" (28). Nuevamente es el tiempo el elemento clave para comprender la diferencia entre los territorios. Ya no solo la referencialidad tecnológica, como resultado cultural, sino, como decíamos anteriormente, como única posibilidad de referencia cultural, Kay, luego indica:

Es como si el aparato, de hecho invisible en la toma, fuera lo efectivamente grafiado y expuesto, como si emanara de aquellas intemperies sorprendidas, de aquella humanidad descolocada, una materia sensible y efectiva que registra a la cámara incrustándola indescifrada en su aura transparente, como un fósil ignoto (29).

Este despliegue teórico nos revela que, finalmente, la única referencialidad posible en la fotografía es el propio dispositivo que satura de significado al objeto frente a la cámara, más si es extraño al campo cultural del aparato. Su invisibilidad es la clave engañosa para los efectos de identificar los modos de operar culturalmente, no se ve la cámara y no se ve el fotógrafo; no se ve al cura salesiano o al cura alemán que producen las fotografías de los fueguinos a inicios del siglo xx y no se ven los franceses de La Romanche que fotografían en el siglo XIX a los mismos sujetos. Esta desaparición esconde al campo cultural que le dio origen a la fotografía y a quienes las encarnan en todas sus acciones, a aquellos que las reproducen sin tener conciencia de ello y por esto se llena de una aparente objetividad. Pero en la observación crítica, todo lo que aparece en la imagen no es el referente, sino su propio sistema de producción.

En "La historia que falta" Kay ingresa al asunto de la temporalidad desde otro lugar, desde otro modo de comprender esto que siempre se escapa a la razón. En este caso, refiriéndose a las estrategias que utiliza Dittborn en su trabajo, se instala en el ámbito aurático benjaminiano para pensar la estrategia histórica de recuperación de ciertas imágenes. El aura, como núcleo teórico, expone la necesidad de tematizarse desde las posibilidades de recuperación de contenidos alejados temporalmente y que cobran mayor relevancia cuando esa actualización se da en el marco del reconocimiento de coordenadas comunes que hacen que en este exista identificación y valorización. Esta Kay la nombra como "nostalgia”; la recuperación aurática no es más que una pura nostalgia, como deseo de recuperar desde la historia algo que ya no está en su tiempo, sino que desplazado o más bien detenido en un tiempo otro. Pero este viaje al pasado es para recuperar al presente. Esto lo dice sobre Dittborn, pero es su interpretación de las posibilidades de su propia comprensión del tiempo, pero este inevitablemente comporta un riesgo grave: la desaparición permanente. La esperanza está en las energías que quedan impresas en los signos, ya no solamente fotográficos, sino de 
toda índole, pero siendo el fotográfico el privilegiado. En este lugar debemos hacer la pregunta sobre los alcances y dimensiones que esta recuperación puede tener. El reconocimiento del aura benjaminiana exige una serie de requisitos para su efectividad, como la pertenencia a la tradición que le dio origen y el dominio de los elementos que han incrementado dicha aura, con el fin de poder reconstruir, precisamente, el valor aurático. Esta exigencia es fundamental en tanto la posibilidad de comprender las coordenadas culturales de su aparición. Pero esta pertenencia plantea, además, que quien pertenece a dicha tradición revela una determinada experiencia que tensiona la reproducción técnica. Los conceptos que se entrelazan críticamente, son, entonces, nostalgia y experiencia a través de la reproducción técnica fotográfica. Son dos conceptos que exponen distintas variaciones de la temporalidad; la primera, desde lo ido irrecuperable; la segunda, desde una cercanía mediada técnicamente. Si pensamos respecto del tiempo desde la «experiencia», esta siempre indica lo pasado. Las dos posibilidades de la "experiencia" implican un acontecimiento ocurrido tiempo atrás: si hablamos de "yo tuve una experiencia", en tanto hecho vivido, necesariamente nos dice de algo que ocurrió y que lo afectó en el mismo acontecer, o sea hecho y sujeto se co-pertenecen para que haya experiencia de este modo. La segunda posibilidad es la experiencia, en tanto acumulación de acontecimientos que le entregan al sujeto cierto conocimiento particular acumulado: "mi experiencia en el trabajo...", por ejemplo. En este caso, también la experiencia indica lo pasado como suma de hechos que en su acumulación singularizan a un sujeto respecto de otro por su conocimiento sobre algo en particular. Lo evidente, como ya decíamos, es que para que exista experiencia, debe transcurrir el tiempo, y el sujeto es donde se operativiza la temporalidad como proyección hacia el futuro.

La fotografía es capaz de hacer aparecer una dimensión extravagante en la conciencia de quien la observa, una virtualidad, en tanto posibilidad de cohabitación de dos extensiones: la temporal y la espacial que imagina una realidad material inexistente. Y esto lo confirma en "Addenda" cuando define a la imagen como la intersección entre tiempo y espacio. El espacio es una posibilidad y el tiempo es la demora...en la administración de ese territorio. Dos dimensiones complementarias colisionan transformándose en la «catástrofe cósmica» que es la fotografía, como lo dice en "El tiempo que se divide". El devenir de la demora en la posibilidad se transforma en imagen técnica; lo importante de esta fórmula es que necesariamente está referida a quienes la usan y a quienes y qué aparecen en ella. Pero más arriba decíamos que el referente del tiempo es el sujeto que lo piensa, a pesar de la normalización técnica que trabaja del mismo modo allá que acá. Pero en este orden, justamente lo técnico evidencia la diferencia referencial.

Indudablemente, la tesis de Benjamin, de la función cultural de la fotografía, está presente en Kay, pero como a él le interesaba destacar, no solo Benjamin, pero resulta evidente que la referencialidad teórica está sostenida fundamentalmente por este filósofo. Si la colisión que ya mencionábamos es la razón de la catástrofe 
cósmica, es porque es primera vez en la historia de la humanidad que es posible que se dé este choque que tiene como resultado un objeto insólito, pero necesario. Esta colisión es una anomalía, un desajuste fundamental que descoloca al acontecer por su fuerza icónica-indicial. Si las cosas eran las portadoras de su propia imagen y la fotografía la emancipa (acá el aura benjaminiana toma forma en Kay), la intersección se transforma en la nueva dimensión existencial, por lo tanto lo que entra en crisis es la posibilidad de la "identidad".

"Cuadros de honor" observa críticamente esta pérdida en las fotografías de registro policial y además en las fotografías de carnet.

Kay nos dice:

En la foto carnet, el rostro humano es encuadrado, encasillado, encerrado y tipificado por el orden, escenificando todo un simulacro de identidad, puesto que en el lapso de su toma, la cara del hombre es sometida a una máxima extorsión; so-pretexto de registrarla en lo que de única y distintiva tiene, la toma, de hecho, hace exactamente lo contrario: aplicándole una y la misma norma fotográfica, la estandariza, cortándola a la medida del orden, y la masifica, multiplicando el orden en ella para que éste se reproduzca mediante ella irrestricta y definitivamente (33).

Lo perdido inexorablemente es cualquier posibilidad de caracterizar alguna identidad. Kay observa, entonces, en este caso, el engaño estructural que presenta la fotografía, el que resulta estar fundado en el prestigio occidental de la calculabilidad: si es medible y calculable existe; del mismo modo que si aparece en una fotografía, existe. El acento no va a estar en la existencia o no de lo fotografiado, sino en los valores asignados y proyectados en los modos de aparecer fotográficos; sería, en palabras de Kay "la pasada de gato por liebre" (33). Estos tendrían la capacidad de entregar fehacientemente al referente. Lo que Kay observa de modo muy original es lo que Flusser más tarde llamó el "programa fotográfico", lo que no es más que el sometimiento de lo fotografiado a los términos que el dispositivo impone. Esto tiene como consecuencia la necesidad de conocer los métodos en que la mediación fotográfica opera, al modo de contraste que figura la diferencia. Si el rostro humano, constreñido al cuadro fotográfico, pierde su posibilidad metonímica, es porque la imagen técnica elimina la posibilidad de llenar el espacio vacío que produce. La fotografía es una cita de la humanidad, pero cita que como el mismo Kay planteó, para el control y no para el conocimiento. ¿Qué identidad podemos encontrar en la fotografía? La identidad de quien ejerce el poder. La mirada se occidentaliza, no tanto en la significación contenida en la superficie de la imagen, sino más bien, en la réplica del gesto colonizador, controlador, del referente que le dio origen.

Ronald Kay explicaba que Del espacio de acá, señales para una mirada americana es pura teoría; es un ejercicio especulativo a modo de ensayo para abrir las posibilidades de desarrollar pensamiento. La metáfora, el lenguaje poético, permitirán 
proliferaciones explosivas de sentidos, liberándose de la estrechez conceptual de la academia, pero podríamos agregar que esta filosofía poética es fundamentalmente política porque nos obliga a pensarnos y definir una significación de nuestro lugar en Occidente, de autorreferenciarnos o de asumir una subordinación inconsciente.

El tiempo y la referencialidad es el núcleo problemático que este autor y texto nos ponen sobre la mesa para ser pensados. Dos dimensiones que, junto con la mecánica, cubren las variables que sostienen las posibilidades culturales y por esto simbólicas de la fotografía. Esta estructura toma diverso tono según el lugar y tiempo en que opere, pero no solo esto, sino que evidencia que no existe regularidad espacial y temporal a lo largo de la extensión natural y que, por el contrario, este dispositivo expone las diferencias claves en las posibilidades referenciales. En la nota a pie de página de "Addenda" nos indica expresamente que la fotografía fija el significante para significados siempre cambiantes, siempre contextuales. Retomando la pregunta con que iniciábamos este texto, el mapa mental por trazar se dibuja desde el correlato simbólico y nunca material que evidencia la diferencia referencial entre los espacios puestos a prueba.

\section{Referencias}

Flusser, Vilem. Hacia una filosofía de la fotografía. México, Trillas, 1990.

Kay, Ronald. De espacio de acá. Señales para una mirada americana. Santiago de Chile, Ediciones Nómade, 2009.

Rojas Mix, Miguel. Los cien nombres de América. Barcelona, Lumen, 1991. 